\title{
Oxygen Therapy in the Home
}

\author{
R. S. MCNEILL,* M.D., F.R.C.P.ED. ; JOYCE M. WATSON,* M.B., D.OBST.R.C.O.G.
}

Brit. med. f., 1966, 1, 331-333

Though the problems of oxygen therapy in patients with respiratory failure in hospital have been widely discussed in our journals in recent times, little attention has been paid to the use of oxygen in the home. It may be felt that this form of treatment is too hazardous and difficult to be contemplated outside hospital, but often there are special factors which persuade practitioners to prescribe oxygen for home use. Thus the patient may have become psychologically dependent on his oxygen cylinder as the result of previous treatment in hospital, or his exercise tolerance may be so restricted that minor household activities are impossible without the help of additional oxygen. In an acute exacerbation of long-standing chronic respiratory disease the humane decision may be to treat the patient at home rather than impose yet another hospital admission, and in these circumstances the risk of oxygen therapy may be acknowledged and accepted. Almost certainly there are other reasons for oxygen therapy in the home, and it is probable that the custom varies from district to district, but since so little is known of the extent to which it is used we thought that it would be of interest to record our observations of the current practice in Dundee.

\section{Methods}

In January 1965 the 95 general practitioners in Dundee (population 185,000) were asked how often they had prescribed oxygen for home use in 1964 and whether they had any patients currently on oxygen. There was an excellent response from the practitioners, and with their permission we were able to visit all patients on oxygen at home.

A history was taken and the peak expiratory flow (P.E.F. $1 . / \mathrm{min}$.) was measured by the Wright meter. The area over the brachial artery was anaesthetized and an arterial blood sample was taken while the patient breathed room air. The arterial $\mathrm{PCO}_{2}$ was measured by the rebreathing method of Campbell and Howell (1960), and then the patient at rest breathed oxygen from his cylinder for 30 minutes. Towards the end of this period the second arterial blood sample was taken and afterwards oxygen was discontinued.

Arterial blood samples were put into a vacuum flask containing ice immediately they were obtained and taken back to the laboratory for measurement of $\mathrm{pH}$, plasma $\mathrm{CO}_{2}$ content by the manometric Van Slyke apparatus, and oxygen saturation by the Kipp haemoreflector.

The gas samples for measurement of $\mathrm{PCO}_{2}$ by the rebreathing method were also taken back to the laboratory for analysis. Previous tests had shown that the concentration of $\mathrm{CO}_{2}$ in the rubber bags fell only by approximately $0.1 \%$ over a two-hour period.

\section{Results}

Table I shows how often oxygen was used in 1964 and the number of patients who were on oxygen in January and February 1965. Some practitioners prescribed oxygen more often than others, and more than half (57\%) had found no occasion to use it at all during this period, although, of course, they may have done so previously.

* Therapeutics Unit, Maryfield Hospital, Dundee.
Of the 22 patients receiving oxygen therapy during January and February 1965 all except one were seriously disabled by chronic respiratory disease and were confined to the house for most of the winter months. The exception had had a pneumonectomy for bronchial carcinoma which had left him with little respiratory disability, but he was also severely hypertensive and was prone to bouts of left heart failure. Nearly all patients used oxygen after slight exertion, such as small household chores or dressing and undressing. These activities were sufficient to bring on marked dyspnoea, which was said to be relieved within a minute or two by oxygen. If patients suffered an exacerbation of bronchitis or asthma they tended to use oxygen at rest and often during the night hours for periods of 5 to 15 minutes at a time. Two patients had recently fallen asleep during the night while on oxygen, and in one this eventually proved to be fatal (see below). The other wakened after about two hours on oxygen when the mask slipped off his face, and he felt unwell during the following day.

TABLE I.-Oxygen Therapy at Home

\begin{tabular}{ccc|cc|c}
\hline & & & & Patients & $\begin{array}{c}\text { No. of Prescribing } \\
\text { Practitioners }\end{array}$ \\
\hline 1964 (Jan.-Feb.) & $\cdots$ & $\cdots$ & $\cdots$ & 56 & 35 \\
1965 (Jactitioners have not used oxygen.
\end{tabular}

All patients used the Polymask supplied by the British Oxygen Company, and oxygen was delivered from a $48 \mathrm{cu}$. $\mathrm{ft}$. (1.36 cu. m.) cylinder at a fixed flow of 2 or $41 . / \mathrm{min}$. through a standard regulator with medium and high settings. This provides an alveolar oxygen concentration of approximately $45-60 \%$. Measurement of the flow of oxygen through one of these regulators showed constant flow rates until the oxygen cylinder was nearly empty. The Polymask fitted poorly in 13 of the 22 patients, and in some the elastic holding the mask to the head was weak and ineffective. All patients were conscious of the fire hazard with oxygen, but the frequent proximity of the cylinder to coal or gas fires showed that this was not taken very seriously.

Details of the patients, with their arterial blood gas findings before and after oxygen, are shown in Table II. There was good agreement between the rebreathing method of calculating arterial $\mathrm{PCO}_{2}$ and the method by which it is derived from $\mathrm{pH}$ and plasma $\mathrm{CO}_{2}$ content. The latter method has been used except when arterial puncture failed or we did not get an adequate sample. As can be seen, the increase in oxygen saturation was accompanied by a rise in $\mathrm{PCO}_{2}$ and a fall in $\mathrm{pH}$. The average rise in $\mathrm{PCO}_{2}$ was $9 \mathrm{~mm}$. $\mathrm{Hg}$ over the half-hour, and there was no difference between those receiving oxygen at 2 or $41 . / \mathrm{min}$. One patient (Case 13) was too ill to be given oxygen by Polymask, and he was admitted to hospital as an emergency and given oxygen at $2 \mathrm{l} . / \mathrm{min}$. by the Edinburgh disposable mask (British Oxygen Company), which provides an inspired concentration of $27-31 \%$ oxygen.

\section{Discussion}

On the whole we were surprised to find that oxygen was used so widely in domiciliary practice. The frequency with which individual patients make use of their oxygen does, of course, vary, but it seems probable that in this area there are 
as many patients using oxygen at home as in hospital. Though oxygen appeared to be used mainly for the relief of effort dyspnoea, patients quite often used it at rest, particularly during an exacerbation of their illness, to ease their breathing or to try to forestall admission to hospital. This is potentially a much more dangerous way of using oxygen than on or immediately after exertion, and it was with this in mind that we attempted to assess the risk by measuring the blood gases before and after 30 minutes of oxygen therapy at rest. The arterial $\mathrm{PCO}_{2}$ at rest and while breathing room air was above $50 \mathrm{~mm} . \mathrm{Hg}$ in 12 of the 22 patients, and because of their chronic hypercapnia these patients must be regarded as being especially vulnerable to uncontrolled oxygen therapy. Furthermore, in six of them the $\mathrm{pH}$ fell to 7.30 or less after 30 minutes, indicating that they had very little reserve buffering power in the blood to cope with a period of hypoventilation and $\mathrm{CO}_{2}$ retention resulting from oxygen therapy.

Hutchison, Flenley, and Donald (1964) have drawn attention to the danger of severe respiratory acidosis when oxygen is given in high concentrations, and Campbell (1964) states that his practice is to restrict the initial inspired oxygen concentration to $25 \%$ in the treatment of a patient suffering from an acute exacerbation of chronic respiratory disease if the arterial $\mathrm{PCO}_{2}$ is above $50 \mathrm{~mm}$. Hg. Since a flow rate of 2-4 1 . of oxygen a minute through a Polymask results in an alveolar oxygen concentration of approximately $45-60 \%$ there is manifest danger in providing this type of mask for this type of patient at home.

This is exemplified by patient Case 13, who had the misfortune to fall asleep in the night hours with his Polymask on, only to awaken in a confused and distressed state about two to three hours later when the oxygen cylinder had run out. His wife supplied the reserve cylinder and during the next four days he used oxygen for short periods with increasing frequency. When he was seen on the morning of the fourth day he was restless, twitching, and confused, and while breathing room air was deeply cyanosed. He had accumulated a dangerous amount of $\mathrm{CO}_{2}$ both in his body and in his alveoli which further reduced the alveolar oxygen tension and resulted in severe arterial desaturation. He was admitted to hospital as an emergency and trial was made of controlled oxygen therapy by the Edinburgh disposable mask (inspired oxygen concentration of approximately $30 \%$ ). A precipitous rise in $\mathrm{PCO}_{2}$ indicated that this had failed and tracheostomy with positive-pressure ventilation was necessary. There was temporary improvement, but the patient developed a myocardial infarction and died after he had been one week on the respirator. There was no evidence of bronchopneumonia at post-mortem examination, and this serious episode of respiratory failure could be attributed solely to his falling asleep while breathing oxygen from a Polymask. It seems reasonable that this type of patient, with chronically raised arterial $\mathrm{PCO}_{2}$ and oxygen desaturation, should be provided with a mask that delivers oxygen at $30 \%$ or less, such as the Edinburgh disposable mask or the Ventimask as supplied by Oxygenaire.

As has already been said, many patients used oxygen after exertion for the relief of dyspnoea, and this was always claimed to be successful. Since additional oxygen after exertion cannot enable the patient to prolong his exercise or reduce the demand on cardiac or respiratory function during exercise, this is an illogical way of using oxygen. Elbel, Ormond, and Close (1961) have shown that when athletes breathe $100 \%$ oxygen after exercise repayment of the oxygen debt is not significantly facilitated, though there is a slight decrease in pulse and respiratory rate. The situation with patients suffering from chronic respiratory disease is nevertheless different, and Huckabee (1965) has shown that emphysematous patients with lowered arterial blood oxygen tensions may fail to deliver the oxygen required by the tissues during moderate exertion because of pulmonary dysfunction rather than impairment of the cardiovascular response. In these patients oxygen after exertion should certainly facilitate the repayment of the oxygen debt and relieve dyspnoea by reducing the anoxic stimulus to ventilation.

Cotes (1965) states that the majority of patients, though not all, disabled by chronic respiratory disease improve their effort tolerance by breathing additional oxygen during exercise. $\mathrm{He}$ recommends that patients should be tested to see if additional oxygen genuinely prolongs the time that they can continue with a given exercise before a decision is taken to prescribe portable oxygen. The principal requirements for portable oxygen are that the apparatus should be light and that the mask delivering oxygen should be provided with a valved reservoir bag to preserve oxygen and prevent the rebreathing of $\mathrm{CO}_{2}$. Cotes and Gilson (1956) described suitable portable equipment, and there is now a choice from several companies, among whom are British Oxygen, Normalair Ltd., Siebe Gorman Ltd., and Walter Kidde Ltd. From the point of view of general practice, the greatest drawback is that portable oxygen equipment cannot be prescribed on an E.C.10 form and must be either borrowed from a hospital or privately purchased. In default of portable oxygen, a long length of lightweight plastic tubing

TABLE II.-Oxygen Therapy in the Home

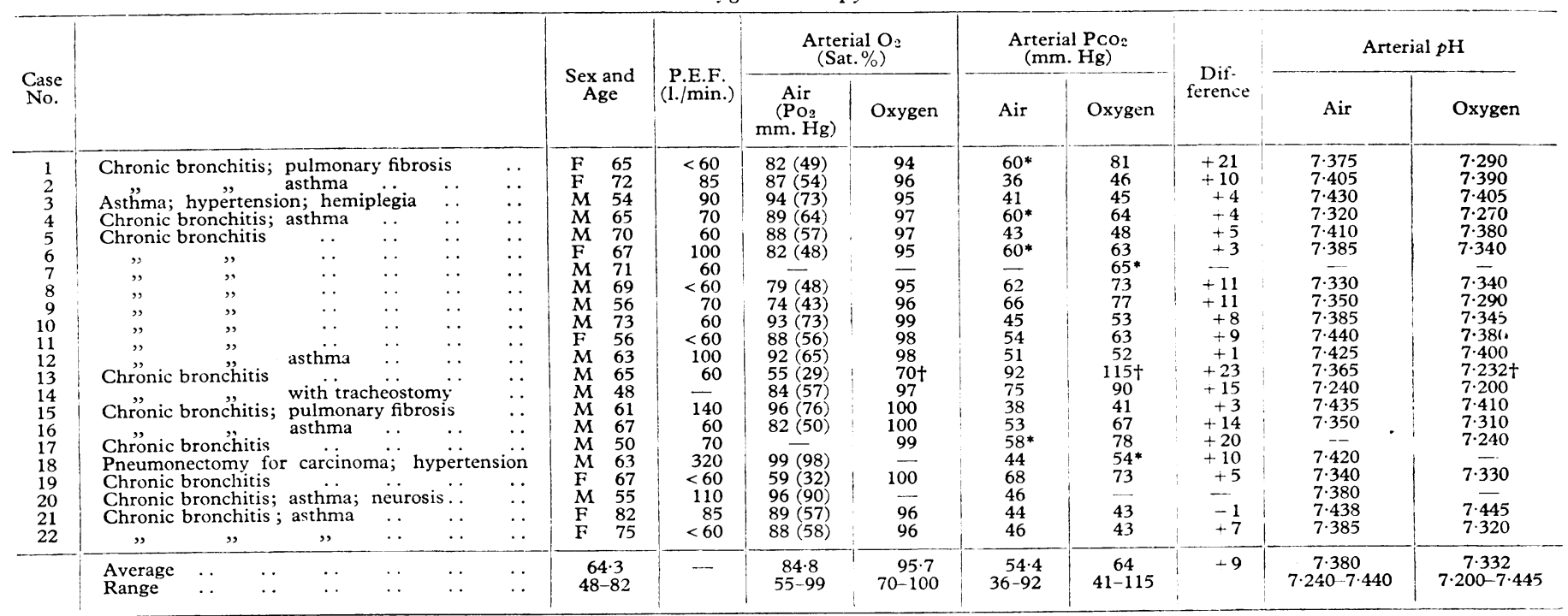


may be used to connect the patient to a static cylinder and so enable him to get about within a restricted area with less distress. The Polymask is unsuitable for portable oxygen because, unless there is a high flow of oxygen, the lack of a non-return valve allows $\mathrm{CO}_{2}$ to accumulate within the mask, and this in itself increases the ventilatory requirements of the patient both at rest and on exercise (Cotes, 1962). Suitable masks that avoid this are available from Siebe Gorman Ltd. and other firms.

Most patients receiving long-term oxygen therapy in the home suffer from chronic respiratory disease and have been in hospital previously. Because of this it should be possible for the hospital staff to assess patients before discharge with a view to advising general practitioners of the possible value of oxygen and the best method of administration. In chronic respiratory disease oxygen at rest is unlikely to provide worth-while benefit unless the patient is breathless at rest because of severe anoxia. It is very probable that this type of patient will have chronic hypercapnia also (arterial $\mathrm{PCO}_{2} 50 \mathrm{~mm}$. $\mathrm{Hg}$ or more) and, if so, oxygen should be provided by a mask that delivers a concentration of not more than $30 \%$. Even then very careful supervision is required during an exacerbation of the illness if an attempt is made to treat the patient at home. If the patient is capable of limited exercise which causes distressing breathlessness or if he would like to be more active, consideration should be given to the provision of oxygen during exercise by one of the methods described. For those with chronic hypercapnia the provision of $30 \%$ oxygen will increase effort tolerance, though not to the same degree as concentrations of $50-60 \%$ (Cotes, 1963). For those without hypercapnia or severe anoxia oxygen therapy may still be worth while for the relief of effort dyspnoea, but the success of this largely depends on the provision of efficient portable apparatus.

\section{Summary}

Current practice in the use of oxygen in the home in Dundee is described. Forty-three per cent. of the general practitioners had prescribed it at least once over a period of 14 months. Twenty-two patients were receiving oxygen at home during the period of study in January and February 1965, and nearly all were seriously disabled by chronic respiratory disease.

Oxygen was used both at rest and after exertion for the relief of dyspnoea and was delivered by Polymask at a flow rate of 2 or $41 . / \mathrm{min}$. from a static cylinder. Arterial blood gas measurements showed that 12 of the 22 patients suffered from hypercapnia (arterial $\mathrm{PCO}_{2} 50 \mathrm{~mm}$. $\mathrm{Hg}$ or more) while breathing room air at rest. The dangers of delivering oxygen by Polymask in this type of patient are discussed and illustrated by the rapid deterioration of one patient who fell asleep with his mask on. It is suggested that a patient with chronic hypercapnia should be provided with a mask that delivers not more than $30 \%$ oxygen.

For the relief of effort dyspnoea oxygen should be used during rather than after exertion, but the success of this again depends on the correct choice of equipment and method of administration.

We are grateful to the general practitioners of Dundee for their generous co-operation in this study and to Miss Jane Bowden, Department of Biochemistry, for blood gas analysis.

\section{REFERENCES}

Campbell, E. J. M. (1964). Brit. F. Dis. Chest, 58, 149.

- and Howell, J. B. L. (1960). Brit. med. 7., 1, 458.

Cotes, J. E. (1962). In Design and Use of Respirators, edlted by C. N. Davies. Pergamon Press, London.

(1963). Brit. med. Bull., 19, 31.

(1965). Lung Function: Assessment and Application in Medicine: Blackwell, Oxford.

- and Gilson, J. C. (1956). Lancet, 1, 872.

Elbel, E. R., Ormond, D., and Close, D. (1961). F. appl. Physiol., 16, 48. Huckabee, W. E. (1965). Ann. N.Y. Acad Sci., 121, 723.

Hutchison, D. C. S., Flenley, D. C., and Donald, K. W. (1964). Brit. med. Э., 2, 1159 .

Rahn, H., and Fenn, W. O. (1955). A Graphical Analysis of the Respiratory Gas Exchange. American Physiological Society, Washington, D.C.

- Head, Medical Unit, Thomson Road General Hospital, Singapore. t Late Senior Registrar, Medical Unit, Thomson Road General Hospital,

‡ Senior Registrar, Medical Unit, Thomson Road General Hospital, Singapore.

phosphamide (Endoxana). Hill and Scott (1964) obtained early good results with a course of cyclophosphamide in a patient with systemic lupus who had failed to respond to steroids. Finally, Mackay et al. (1964) used mercaptopurine and azathioprine (Imuran), a derivative of mercaptopurine, with success in three patients with active chronic hepatitis and two with lupoid hepatitis.

From the foregoing it was thought that an ankylating agent like cyclophosphamide, which produces very few serious sideeffects as opposed to steroids, may be of value in the management of S.L.E. Since 1963 all newly diagnosed cases of S.L.E. admitted to the unit have been treated with cyclophosphamide.

So far 15 patients have been treated with this cytotoxic agent but only nine have been followed up long enough for assessment (for periods varying from 3 to 27 months). Below we discuss the response of these nine patients to this form of therapy. 